\title{
Effective biodiesel synthesis from waste cooking oil and biomass residue solid green catalyst
}

\begin{abstract}
Biodiesel has recently received greater concern as one of the reliable and sustainable source of energy. Production of biodiesel is hampered by both feedstock availability and catalyst system. This work successfully utilized the waste egg shell to develop a bimetallic mixed oxide catalyst, and waste cooking oil characterised by high free fatty acid (FFA) as feedstock, towards methyl ester production under mild reaction condition in one-step transesterification process. The properties of the catalyst were assessed using XRD, BET, SEM, EDX and TPD$\mathrm{CO}_{2}$. The prepared catalyst was successfully recorded a high biodiesel yield of $92.1 \%$ under the optimized reaction conditions of 15:1 methanol to oil molar ratio, $3 \mathrm{wt} \%$ catalyst loading, $80^{\circ} \mathrm{C}$ reaction temperature and $3 \mathrm{~h}$ reaction time. The recovered catalyst was reused in five cycles without significant loss in activity. The leaching of catalytic $\mathrm{Ca}^{2+}$ active site was reduced when transition bimetallic mixed oxides were added to the $\mathrm{CaO}$ surface.
\end{abstract}

Keyword: Biodiesel; Bimetallic mixed oxide catalyst; Waste cooking oil; Leaching of $\mathrm{Ca}^{2+}$ metal ion 